\title{
Implementation Of FEDI: A Pilot Study On The Banking Industry In Malaysia.
}

Murali Raman, (murali.raman@mmu.edu.my), Multimedia University Malaysia Saravanan Muthaiyah, (saravanan.muthaiyah@mmu.edu.my), Multimedia University Malaysia

\begin{abstract}
Financial Electronic Data Interchange (FEDI) refers to making cash payment electronically rather than utilizing any from of traditional payment methods such as checks The prime objective of this paper is to ascertain how is FEDI currently being implemented byl0 anchor banks in Malaysia. Specifically this paper examines the current business process that facilitates transfer of payment received by banks to its various agents. The paper also examines the security or precautionary measures established by anchor banks while engaging in financial electronic data interchange.
\end{abstract}

\section{Overview}

nter-organizational and intra-organizational connectivity using computer networks is an important business requirement today (Dove, 1999). This means, an organization must be able to communicate instantly with other organizations to exchange information and to perform business transactions as well as communicate internally between the various business units (e.g., departments or regional offices) to share and exchange information. Such connectivity is vitally important in today's fast-paced world in order for a business to remain effective, efficient and competitive. This has been enabled to a large extent in recent years by the increased use and availability of information technology (IT) and the development of the World Wide Web. Companies can share information and hence knowledge more readily (Kalakota, R. and Whintston 1996). It allows them to take a more holistic view of their business processes. Both businesses and Governments have realized that the advent of the electronic era has created opportunities along with threats (if businesses/governments do not react!) within a particular economy. A major force driving Knowledge Economy is creativity and innovative capability. An example of creativity and innovation is utilization of the Internet for business e.g. Amazon.com uses the Internet to sell books. Governments establishing interactive broad band infrastructure that allows society in general to very quickly download information and communicate using technologies such as teleconferencing, videoconferencing and other Internet and wireless based application is another example. Other aspects of creativity and innovation are digitization, convergence and interactive broadband creation within an economy. Changes within economies as a result of creative and innovative technology are continuously reducing operations cost for government and businesses alike. A survey conducted by OECD recently suggests that Internet banking has reduced transaction costs from US $\$ 1.08$ per transaction to US $\$ 0.13$ per transaction ${ }^{1}$.

\section{Study Objectives And Research Questions}

Financial Electronic Data Interchange refers to making cash payment electronically rather than utilizing any from of traditional payment methods such as checks The prime objective of this paper is to ascertain how is FEDI currently being implemented by anchor banks in Malaysia. Specifically this paper examines the current business process that facilitates transfer of payment received by Anchor banks to its various agents. The paper also

\footnotetext{
${ }^{1}$ Source: MDC
} 
examines the security or precautionary measures established by Anchor banks while engaging in financial electronic data interchange. Specific research questions that this paper aims to address are as follows:

- To what extent has the implementation of FEDI led towards simplification and non-duplication of work for banks and its agencies?

- To what extent has the implementation of FEDI by banks led towards wages and stationary cost reduction?

- $\quad$ Does the implementation of FEDI lead to greater transaction volume?

- Has FEDI reduced the idle cash float due to the participating agencies?

- Does FEDI provide a platform for enhanced Customer Relation Management (CRM) amongst Anchor banks?

\section{Related Research}

Electronic data interchange is an application that emerged in the late 1960's as a communications tool that enables companies within a particular industry to exchange a wide range of business documents such as including purchase orders, invoices, shipping orders and confirmations which are manifestations of standard business processes in any business transactions (Bejamin et al, 1990; Swatman, 1994).

Over the last two decades, EDI systems have provided viable means for utilization of technology to facilitate cross border and inter-organizational transactions (Sokol 1989, Emmelhainz 1993, Farhood and Pace, 1995). Most research on EDI however focus on requirements to ensure these systems works with much emphasis on technical issues such as integrating EDI them into existing applications (Georg 1993). Nevertheless there studies which focus on improvements in efficiency (Mukhopadhyay et al. 1995) and analysis of environmental conditions and success factors for fast and broad technology diffusion (Pfeiffer 1992, Bouchard 1993).

With the rapid expansion of the Internet, there are a number of initiatives underway for the creation of a secure cost-effective payment system, which will be able to support growing activities in the network (Ravi and Robinson, 2001, Gosh 2000). Although electronic payment systems to facilitate large payments have been in operation for quite some time, expanding transaction volumes are increasing the pressure for cost-effective and efficient electronic payment systems. A number of factors, including drastically reduced costs of computing hardware, software and telecommunications combined with the lifting of trade barriers across Europe mean that EDI is moving from an embryonic, innovative phase into a phase of exponential global growth. Another major factor is the increasing realization of the role of EDI as a business enabler to increase competitive and dynamic markets. EDI (electronic data interchange) can be conceptualized as a member of a family of technologies for communicating business messages electronically, including facsimile (fax), electronic mail, telex, and computer conferencing systems (bulletin boards). Businesses use each of these technologies to exchange commercial messages with their respective trading partners. The boundaries between these technologies are not rigid. A message may, for example, begin as an EDI message, but later be converted (by perhaps an intervening network provider) into fax or e-mail format before its ultimate delivery.

As electronic commerce is envisioned to become the way to do business in all industries (Gates 2000, Kalakota and Whinston, 1996) financial electronic data interchange (FEDI) and other forms of electronic commerce are speeding transactions, improving customer service and reducing costs for companies of all sizes. Corporations, government agencies and entire industry segments are expected to demand a full range of financial EDI services. Providing these services would be essential for organizations that intend to retain and grow within the domain of payments and cash-management business.

Electronic data interchange (EDI) is commonly defined as the application-to-application transfer of business documents between computers. Many businesses choose EDI as a fast, inexpensive, and safe method of sending purchase orders, invoices, shipping notices, and other frequently used business documents. Nevertheless EDI is quite different from sending electronic mail messages or sharing files through a network, a modem, or a bulletin board. The straight transfer of computer files requires that the computer applications of both the sender and 
receiver (referred to as "trading partners") agreeing upon a predetermined format of document. The sender must use an application that creates a file format identical to that of the receiver.

\subsection{Benefits Of EDI}

Initial EDI applications have concentrated on corporate efficiency by improving data flow and error reduction. In these instances the business case for EDI was based primarily on direct cost savings. Genentech, Inc. a leading pharmaceutical manufacturer and biotechnology research firm based in San Francisco - continually seeks faster, more economical, and more efficient ways to get its products into the hands of customers. ${ }^{2}$ Genentech's sales and marketing department determined that improved customer service and reduced costs could be achieved by introducing EDI technologies into the sales order cycle. Today Genentech is reaping the many rewards of an integrated EC implementation that includes several custom-built EDI tools. Benefits include amongst others, significant reduction in data-entry errors, and faster product shipment to the manufacturer's customers. The most noticeable benefit has been the reduction of time required to process orders. At the end of their first year of EDI purchase orders, the order department expects to realize savings equivalent to the salary of one full-time staff member. Electronic commerce and EDI are assisting Genentech to save money, while offering it with the ability to enhance customer relationship management.

In addition to reducing direct cost, EDI also has the ability to increase labor efficiency. A study on Kessler Industries Incorporated, a family-owned manufacturer of metal indoor and outdoor furniture is a case in point. In the early 1990s, Kessler began doing business electronically with a large retailer, and as more customers became interested in EDI, the company sought to expand and integrate its electronic commerce initiative. In order to create a link between EDI and their manufacturing system, the company utilized EDI translation and integration software to link EDI to its internal applications and to create customized templates for documents such as purchase orders, invoices, advance ship notices and price/sales catalogs. The benefits of Kessler's integrated EDI system include improved customer service and customer satisfaction, labor savings and improved accuracy.

Utilization of EDI to transmit invoice data and payments can improve a company's cash flow management while increasing the amount of working capital, achieved via efficeint account handling. A case in point is ShopNet Singapore, an industry-wide integrated information technology (IT) community developed jointly by Singapore Article Number Council, the Retail Promotion Centre and the National Computer Board for small retailers in housing estates. ShopNet empowers small retailers in Singapore to conduct point-of-sales (POS) scanning, inventory control and EDI for procurement pruposes. Currently, there are 170 retailers and 38 major suppliers participating in the ShopNET project. Benefits cited by retailers participating in the project include:

- $\quad$ access to vital product information from suppliers;

- $\quad$ store specific product mix for better customer service;

- $\quad$ standardization of product code and symbols;

- $\quad$ electronic tracking of product movement at each store;

- $\quad$ improved cash flow through increase in stock turnover and reduction of inventory;

- $\quad$ daily electronic sales and profit reporting on a store by store basis. ${ }^{3}$

In summary, from the perspective of Anchor banks, based on comtemporary review of literature, the implementation of the financial EDI would include increasing the speed of posting of funds through increased automation and processing accuracy.

\subsection{Development Of Payment Systems}

Markets of any sort involve transactions, right through to the point when the buyer has paid the seller. Until that point, the whole transaction remains uncertain. The more traditional a payment system, longer the delay is

\footnotetext{
${ }^{2}$ http://www.annexb.com/, Across Asia Pacific : Examples of Electronic Commerce Uses

3 http://www.annexb.com//, Across Asia Pacific: Examples of Electronic Commerce Uses
} 
expected between undertaking to pay and actual receipt of payment which increases the default risk. The Internet offers the prospect of a highly cost-effective payment system for low value transactions which includes micropayments. The technologies involved are able offer settlement of transactions on the fly. However, the fundamental difficulty with establishing electronic payment systems on the Internet is that, a system which is specifically designed to facilitate the free exchange of information could subject to security threats. In order to achieve such an objective, security issues will need to be successfully addressed to ensure full benefits of FEDI systems are achieved. Currently, Internet customers do not have a limited set of options for making payments. However, as the Internet is now acquiring a more commercial character, organizations are pressured to develop and market a form of electronic payment system that will be as fast, flexible and global as the Internet itself (see for example Turban, Lee and King, 2002, Ravi and Robinson 2000).

There are at present several approaches to achieving a secure payments solution. Most involve some form of encryption to protect the confidentiality of the sensitive elements of the message. A second line of approach is for a payment service provider to act as a messaging intermediary, often using other established security clearance procedures.

Encryption has become a key element in discussions concerning commerce on the Internet. Two most common type of encryption technology are the private-key cryptography and the public-key cryptography. Publickey cryptography makes it possible to 'sign' a document so that the recipient can be assured that the source of the message is authentic as well as to 'seal' a document, ensuring that no one except for the recipient can open or change it. The encryption technology will be based on algorithms that have been developed by the company. Encryption facilitates services that require privacy, such as home-banking and electronic money-transfer between businesses.

\section{Methodology}

This is an exploratory research, where not much is known about the situation at hand, and information is scarce on the research issues that have been resolved previously. Thus, the main reason of this research is to generate more knowledge and improve understanding on the FEDI concept.

This research is based on qualitative approach that relates to a test or measurement, which determines the usefulness of Financial Electronic Data Interchange within the banking sector. Banks that have received anchor banks status in Malaysia are Public Band Berhad, Alliance bank, Bumiputra Commerce bank, Southern bank, Standard Charted bank, United Overseas Bank, EON bank, Hongkong \& Shanghai Bank Corporation, and RHB.

For the purpose of this study, information was gathered through primary and secondary sources. To achieve a more reliable outcome, questionnaires were sent through mail to few banks within the Kuala Lumpur vicinity. Our main focus is on the banks, with well-established presence in Kuala Lumpur, Malaysia. The banks that were chosen are banks that have adopted FEDI.

Table 1 summarizes key hypotheses that were formulated to facilitate this study.

Table 1- Hypothesis

\begin{tabular}{|l|l|}
\hline Hypothesis 1 & $\begin{array}{l}\text { Implementation of FEDI reduces workload, simplification and non-duplication of business } \\
\text { processes }\end{array}$ \\
\hline Hypothesis 2 & Implementation of FEDI systems will reduce wages and stationery cost. \\
\hline Hypothesis 3 & FEDI will increase number of transaction volume \\
\hline Hypothesis 4 & $\begin{array}{l}\text { Implementation of FEDI systems will reduce the idle cash float amount due to participating } \\
\text { agencies }\end{array}$ \\
\hline Hypothesis 5 & $\begin{array}{l}\text { Implementation of FEDI systems increases competitive advantage for an institution as a } \\
\text { result of reduction in commission charged levied to participating agencies. }\end{array}$ \\
\hline Hypothesis 6 & $\begin{array}{l}\text { The implementation of FEDI will provide a platform for effective Customer Relation } \\
\text { Management solutions. }\end{array}$ \\
\hline
\end{tabular}


Hypotheses 1 to 3 are inter-related. Hypothesis 1 which states that the implementation of FEDI will reduce the workload as manual work can be reduced via fully computerized systems which simplifies business processes while reducing non-duplication of work. Hypotheses 4 and 5, suggest that the implementation of FEDI enhances effectiveness and efficiency of business processes and this in turn leads to a reduction of the idle cash float payments due to participating agencies.

This offers the potential of reducing commission levied to participating agencies. These factors will provide a higher satisfaction to participating agencies as they can receive payment earlier. This reduces the opportunity cost of late payment for agencies participating within a FEDI environment. These are prerequisites for providing a platform for superior Customer Relation Management for banks.

\section{Discussions And Findings}

A total of 300 questionnaires were sent by post, email, fax, in addition to personal interviews. Respondents were predominantly from the banking sector that includes Alliance Bank, Bumiputra Commerce Bank, EON Bank, HSBC, RHB, Southern Bank, Standard Chartered, and UOB ${ }^{4}$. Out of this figure only 163 respondents answered the questionnaire, giving this study a response rate of $54 \%$.

\subsection{FEDI Implementation}

An estimated $70 \%$ of the respondents from the financial institutions implemented the system more than 5 years ago.

\begin{tabular}{|l|c|c|c|c|c|}
\hline & & Frequency & Percent & Valid Percent & Cumulative Percent \\
\hline Valid & $1-3$ years & 12 & 7.4 & 7.6 & 7.6 \\
\hline & 3-5 years & 35 & 21.5 & 22.3 & 29.9 \\
\hline & $>5$ years & 110 & 67.5 & 70.1 & 100.0 \\
\hline & Total & 157 & 96.3 & 100.0 & \\
\hline Missing & 9 & 6 & 3.7 & & \\
\hline Total & & 163 & 100.0 & & \\
\hline
\end{tabular}

\subsection{Antecedents Of FEDI Implementation}

Respondents were asked to rank the factors that led to the implementation of FEDI systems. Specific reasons include advancement in computer technology, competition, transaction volume increased, reduced processing \& human error, security of the electronic payment system and others. Table 2 shows the overall ranking of the reasons that contributed to the implementation of FEDI. The most important factor was assigned 6 points, followed by $2^{\text {nd }}$ most important value with 5 points and so on. Total points for all respondents were obtained and were ranked as follows:

\footnotetext{
${ }^{4}$ Please note that only eight out of ten banks participated in this survey.
} 
Table 2 Antecedents Of FEDI Implementation

\begin{tabular}{|c|c|c|c|}
\hline & & Aggrega & \\
\hline Performance Evaluation & Contributing Factors & $n$ & $\%$ \\
\hline Most important & Advancement in computer technology & 817 & 24 \\
\hline $2^{\text {nd }}$ important & Security of the electronic payment system & 691 & 20.2 \\
\hline 3rd important & Transaction volume increases & 587 & 17.2 \\
\hline 4th important & Competition & 567 & 16.6 \\
\hline 5th important & Reduce processing/human error & 547 & 16 \\
\hline \multirow[t]{2}{*}{ Least important } & Others & 205 & 6 \\
\hline & & 3414 & 100 \\
\hline
\end{tabular}

\subsection{Problems During Implementation}

The table below shows the overall ranking of the problem faced in implementing the system. The most important is assigned 4 points, followed by $2^{\text {nd }}$ most important value with 3 points and so on. Total points for all respondents are totaled to determine an overall ranking.

Table 3 Problems In The Implementation Process

\begin{tabular}{|l|l|c|c|}
\hline & \multicolumn{1}{|c|}{} & \multicolumn{2}{c|}{ Aggregate } \\
\hline \multicolumn{1}{|c|}{ Performance Evaluation } & \multicolumn{1}{|c|}{ Problems } & \multicolumn{1}{c|}{$\boldsymbol{n}$} \\
\hline Most important & Cost involve & 534 & 32.8 \\
\hline $2^{\text {nd }}$ important & Agencies reluctance to change to new system & 391 & 24 \\
\hline $3^{\text {rd }}$ important & Time consuming & 354 & 21.7 \\
\hline 4 th important & Management support & 351 & 21.5 \\
\hline & & $\mathbf{1 6 3 0}$ & $\mathbf{1 0 0}$ \\
\hline
\end{tabular}

\subsection{Hypothesis Testing}

\section{Hypothesis 1 - Implementation of FEDI reduces workload, simplification and non-duplication of business processes}

In this hypothesis, the objective is to find out whether the implementation of FEDI has reduced the workload of employees compared to the manual system used from the receipt of payments to the reconciliation of information to the various agencies. The questions that were developed to support the hypothesis are:

- $\quad$ Do you think the FEDI is able to simplify the payment system?

\begin{tabular}{|l|l|c|c|}
\hline & & Frequency & Percent \\
\hline Valid & Yes & 163 & 100.0 \\
\hline
\end{tabular}


- $\quad$ Do you think the FEDI reduces work duplication of the payment system?

\begin{tabular}{|l|l|c|c|}
\hline & & Frequency & Percent \\
\hline Valid & Yes & 163 & 100.0 \\
\hline
\end{tabular}

- Did implementation of this system have an effect upon the payment workload in any way?

\begin{tabular}{|l|l|c|c|}
\hline & & Frequency & Percent \\
\hline Valid & Yes & 123 & 75.5 \\
\hline & No & 39 & 23.9 \\
\hline & Total & 162 & 99.4 \\
\hline Missing & 9 & 1 & .6 \\
\hline Total & & 163 & 100.0 \\
\hline
\end{tabular}

All the 163 respondents agree that the FEDI system is able to simplify and reduce work duplication of the payment system. However $23.9 \%$ respondents disagree that the system has an effect upon the payment workload. According to them, the payment workload has no significant changes although the payment system is simplified and non-duplicated with the implementation of FEDI system. But in overall result, $75.5 \%$ agree that the implementation of FEDI system reduces the payment workload. In this context, the hypothesis can be generally accepted.

\section{Hypothesis 2 - Implementation of FEDI systems will reduce wages and stationery cost.}

This hypothesis is only relevant to the managerial level where they have knowledge on vital financial information within a firm. One respondent from Alliance Bank says that the use of FEDI offers an important cuttingedge benefit to customers to help them compete in today's market. But even the best technology needs the 'human element' to ensure success. Therefore, it is said that while there could be elimination of staff within the existing departments, recruitment of staff in the IT Department, customer relationship and database administration will still be required. The second part of the hypothesis tests on whether stationery cost such as the paper, pen, and space for storage of documents are reduced via the implementation of the FEDI system. Specifically, the following issues were addressed:

- $\quad$ Did implementation of FEDI have an effect upon wages costs in any way?

\begin{tabular}{|l|l|c|c|c|c|}
\hline & & Frequency & Percent & Valid Percent & Cumulative Percent \\
\hline Valid & Yes & 57 & 35.0 & 41.9 & 41.9 \\
\hline & No & 79 & 48.5 & 58.1 & 100.0 \\
\hline & Total & 136 & 83.4 & 100.0 & \\
\hline Missing & 9 & 27 & 16.6 & & \\
\hline Total & & 163 & 100.0 & & \\
\hline
\end{tabular}

- $\quad$ Did implementation of this system have an effect upon stationery costs in any way?

\begin{tabular}{|l|l|c|c|}
\hline & & Frequency & Percent \\
\hline Valid & Yes & 136 & 83.4 \\
\hline Missing & 9 & 27 & 16.6 \\
\hline Total & & 163 & 100.0 \\
\hline
\end{tabular}

$58.1 \%$ of the respondents disagreed that the FEDI system has an effect upon wages costs. According to them, though the employees handling the manual work decreases, but the need for IT staff to operate the system increases at the same time. Thus the effect upon wages costs was not significant. 83.4\% of the respondents agree that the system decreases the stationary costs. 


\section{Hypothesis 3 - FEDI will increase number of transaction volume.}

As technology advancement is evolving rapidly, companies are under more pressure than ever to operate efficiently and cost-effectively. The quickest way to reduce errors and increase competitive edge is through electronic trading communities. Therefore the Financial Electronic Data Interchange (FEDI) is seen as a method of helping businesses to meet this requirement. This hypothesis aims to test whether firms using FEDI are more efficient in terms of processing volume of transactions compared to the traditional manual techniques. The table below suggests that $89.4 \%$ of the respondents agree that the FEDI system increases the number of transaction volume. Therefore, this hypothesis should be accepted.

FEDI will increase number of Transaction volume

\begin{tabular}{|ll|r|r|r|r|}
\hline & & & & & Cumulative \\
& Frequency & Percent & Valid Percent & Percent \\
\hline Valid & Yes & 144 & 88.3 & 89.4 & 89.4 \\
& No & 17 & 10.4 & 10.6 & 100.0 \\
& Total & 161 & 98.8 & 100.0 & \\
Missing & 9 & 2 & 1.2 & & \\
Total & & 163 & 100.0 & & \\
\hline
\end{tabular}

\section{Hypothesis 4 - Implementation of FEDI systems will reduce the idle cash float amount due to participating agencies}

By combining the speed and convenience of technology with highly personalized service, the implementation of FEDI helps operate business transactions more efficiently, thus optimizing the agencies' cash flow and improve their bottom line. Factors that can lead to increase in revenue for the agencies that have implemented FEDI systems is the improvement in fund availability of agencies as paperless transactions increases the speed the posting of funds through the increased automation and improved processing accuracy. This thus creates a strategic partnership between the agencies and the collection intermediaries that will enable the firm to reach out to a larger market. Prior to the implementation of FEDI systems, $100 \%$ of the respondents bank-in the payment to the participating agencies' accounts. Hypothesis 4 can be stated in the null and alternate as follows:

H1 $1_{0}$ : There will be no difference on the idle cash float before and after the implementation of FEDI system. Statistically expressed: $\mathrm{H}_{\mathrm{O}}$ is $\boldsymbol{\mu}_{\mathrm{b}}=\boldsymbol{\mu}_{\mathrm{a}}$, where $\boldsymbol{\mu}_{\mathrm{b}}$ is idle cash float before the implementation and $\boldsymbol{\mu}_{\mathrm{a}}$ is idle cash float after the implementation.

H1 $1_{\mathrm{A}}$ : The FEDI system will reduce the idle cash float. Statistically expressed: $\mathrm{H} 1_{\mathrm{A}}$ is $\boldsymbol{\mu}_{\mathrm{b}}>\boldsymbol{\mu}_{\mathrm{a}}$ or $\boldsymbol{\mu}_{\mathrm{b}}<\boldsymbol{\mu}_{\mathrm{a}}$

A $t$-test was done to see if there are any significant differences in the means for two groups in the variable of interest. That is, a nominal variable that is split into two subgroups (in this case, before and after the implementation of FEDI) is tested to see if there is a significant mean difference between the two split groups. The $t$ test takes into consideration the means and standard deviations of the two groups on the variable and tests whether the numerical difference in the mean is significantly different from 0 (zero) as postulated in our null hypothesis. A $t$ test will indicate if the implementation of FEDI system has an effect on the idle cash float due to the agencies. The result of the $t$-test done is shown in the tables below.

As can be seen, the difference in the means of 3.31 and 1.7 with standard deviation of 1.22 and 0.56 for before and after implementation is significant. The null hypothesis is rejected as the t value falls outside of the region. The means of 3.31 and 1.7 for before and after implementation of the FEDI system indicate that the idle cash 
float reduced from 4-5 days to 1-3 days. Please refer to the scales below. Therefore, it supports the alternate hypothesis that the FEDI system reduces the idle cash float, $\boldsymbol{\mu}_{\mathrm{b}}>\boldsymbol{\mu}_{\mathrm{a}}$.

Scales:

\begin{tabular}{|l|l|l|l|l|}
\hline $1=<1$ days & $2=1-3$ days & $3=4-5$ days & $4=6-7$ days & $5=>1$ week \\
\hline
\end{tabular}

Paired Samples Statistics

\begin{tabular}{|c|c|c|c|c|c|}
\hline & & Mean & $\mathrm{N}$ & Std. Deviation & $\begin{array}{l}\text { Std. Error } \\
\text { Mean }\end{array}$ \\
\hline \multirow[t]{2}{*}{$\begin{array}{l}\text { Pair } \\
1\end{array}$} & $\begin{array}{l}\text { Bef ore the } \\
\text { implementation of FEDI, } \\
\text { what was the lead-time } \\
\text { for a pay ment made until } \\
\text { it was cleared? }\end{array}$ & 3.31 & 162 & 1.222 & .096 \\
\hline & $\begin{array}{l}\text { Af ter the implementation } \\
\text { of FEDI, what was the } \\
\text { lead-time for a pay ment } \\
\text { made until it was } \\
\text { cleared? }\end{array}$ & 1.70 & 162 & .558 & .044 \\
\hline
\end{tabular}

Paired Sample Test

\begin{tabular}{|c|c|c|c|c|c|c|c|c|}
\hline & \multicolumn{5}{|c|}{ Paired Differences } & \multirow[b]{3}{*}{$\mathrm{t}$} & \multirow[b]{3}{*}{$\mathrm{df}$} & \multirow{3}{*}{$\begin{array}{c}\text { Sig. } \\
\text { (2-tailed) }\end{array}$} \\
\hline & \multirow[t]{2}{*}{ Mean } & \multirow{2}{*}{$\begin{array}{l}\text { Std. } \\
\text { Dev. }\end{array}$} & \multirow{2}{*}{$\begin{array}{c}\text { Std. } \\
\text { Error } \\
\text { Mean }\end{array}$} & \multicolumn{2}{|c|}{$\begin{array}{l}\text { 95\% Confidence Interval of the } \\
\text { Difference }\end{array}$} & & & \\
\hline & & & & Lower & Upper & & & \\
\hline $\begin{array}{l}\text { Pair } 1 \text { Before and After the } \\
\text { implementation } \\
\text { of FEDI }\end{array}$ & 1.61 & .851 & .067 & 1.48 & 1.74 & 24.106 & 161 & .000 \\
\hline
\end{tabular}

\section{Hypothesis 5 - Implementation of FEDI systems increases competitive advantage for an institution as a result of reduction in commission charged levied to participating agencies.}

Here the hypothesis aims to test whether commissions can be reduced as a result of lower transaction cost incurred such as call volumes and payment-processing cost due to the implementation of the financial EDI system. One of the characteristics faced by these intermediary collectors in the competitive environment is the 'kinkeddemand' curve whereby if the firm tries to raise its commission, other firms will not follow and thus it will lose more of its sales. In this form of informal collusive behavior, the price or commission rate charged tends to be sticky because if a firm reduces the commission, most of the firm will immediately try and follow suit. 


\section{Did the implementation of the system have an effect upon participating agencies' cost in any way?}

\begin{tabular}{|ll|r|r|r|r|}
\hline & & & & & Cumulative \\
& Frequency & Percent & Valid Percent & Percent \\
\hline Valid & Yes & 152 & 93.3 & 93.8 & 93.8 \\
& No & 10 & 6.1 & 6.2 & 100.0 \\
& Total & 162 & 99.4 & 100.0 & \\
Missing & 9 & 1 & .6 & & \\
Total & & 163 & 100.0 & & \\
\hline
\end{tabular}

93.8\% of the respondents agree that the FEDI system has an effect upon participating agencies' cost. Further analysis reveals that $95 \%$ of the respondents believe that this will lead to a competitive advantage for both banks and participating agencies. Based on the respondents' answer, this hypothesis can be accepted.

\section{Hypothesis 6 - The implementation of FEDI will provide a platform for effective Customer Relation Management solutions.}

Customer relationship management specializes in selected industries in order to understand the needs, trends and special requirements of the customers in the segments they serve. One respondent from Southern Bank says that by having a financial EDI system, the bank is able to deliver value-added solutions to customers that will enable them to more effectively service their employees, while satisfying government regulatory requirements. There are a number of other objectives that can be achieved by the FEDI.These would include:

- $\quad$ A/P payment processing performed by bank;

- $\quad$ Bank reconcilement performed by bank;

- $\quad$ Reduce purchasing to key vendors who could support FEDI;

- $\quad$ Facilities movement to JIT purchasing, if desired;

- $\quad$ Implement EDI invoicing with PO matching;

- $\quad$ Eliminate need for staff increases;

- $\quad$ Lower cost secure way of doing business and

- $\quad$ High customer satisfaction

The table below shows the overall ranking for each of the expectation to be achieved by the implementation of FEDI system. The most important outcome was assigned 8 points, followed by $2^{\text {nd }}$ most important value with 7 points and so on. Total points for all respondents are totaled to determine an overall ranking. 


\begin{tabular}{|c|c|c|c|}
\hline & & \multicolumn{2}{|c|}{ Aggregate } \\
\hline Performance Evaluation & Expectations & $\mathbf{n}$ & $\%$ \\
\hline Most preferred & Happy customers. & 1011 & $17.4 \%$ \\
\hline 2nd preference & Lower cost secure way of doing business and & 883 & $15.2 \%$ \\
\hline 3rd preference & Implement EDI invoicing with PO matching; & 713 & $12.3 \%$ \\
\hline 4th preference & Bank reconcilement performed by bank; & 678 & $11.6 \%$ \\
\hline 5th preference & Eliminate need for staff increases; & 669 & $11.5 \%$ \\
\hline 6th preference & A/P payment processing performed by bank; & 649 & $11.1 \%$ \\
\hline 7th preference & Facilities movement to JIT purchasing, if desired; & 620 & $10.7 \%$ \\
\hline \multirow[t]{2}{*}{ Least preferred } & Reduce purchasing to key vendors who could support FEDI; & 597 & $10.2 \%$ \\
\hline & & 5820 & $100 \%$ \\
\hline
\end{tabular}

Based on the above, we can suggest that the most preferred expectation of FEDI implementation is to improve customers relationship. This is supported by their frequent revision of customer service policies within banks interviewed. $38 \%$ of the respondents update their customer service policy every year. $33 \%$ will have formal policy update constantly based upon client's need and $27 \%$ have rewritten the policy within last 2 years. That means $98 \%$ of the respondents will revise their policy every two years. This implies that Customer Relationship Management (CRM) is of great importance to them in managing and making decisions. In addition, $77 \%$ of the respondents believe that the FEDI system can provide a platform for CRM. According to them, they enjoy a high degree of customer loyalty based upon the current service provided. Rarely there is any formal complaint from endusers or agencies related to the system.

\section{Conclusion}

In summary FEDI implementation can be described as a value-added service, which can enhance service delivery for banks such as security, enabling applications, network optimization, collaboration services and consulting. This helps trading partners, or in this case the agencies involved, to take full advantage of the system, managing the change efficiently, strengthening relationships and discover totally new ways of doing business. The use of financial EDI also improves customer service as the related agencies can access their account information on a 24-hour basis as all payments made are typically applied directly to the agencies' account on the next business day based on individual client billing. This enables customers to receive the level of control they desire, with new levels of convenience and flexibility that make it easier for them to check payment updates and all related information 24 hours a day, seven days a week, 365 days in a year.

\section{Future Study}

The study that has been carried out is a pilot study within the context of banking sector in Malaysia, which has never been explored before by other researcher in the same field. As this is a pilot study, data that has been collected are from primary sources entirely. The restriction on primary data is that it is difficult to put the data into statistical tool for testing purposes relative to secondary data. This may result to imprecision in selection of type of test in testing the information collected.

While conducting the research, the researchers observed that, it was difficult to obtain actual related information, as the banks interviewed were reluctant to disclose such information, which they regard as confidential. The sample size of the study is narrow due to the focus on banking sector predominantly. Thus the research results that have been gathered is unable to represent the whole picture of FEDI implementation within overall Malaysian context. This is one area in which, other researcher could add significant contribution to. 
Despite the convenience of electronic payment alternatives, many consumers prefer the control of payment by traditional modes e.g. check. Even though electronic payment results to faster and more secured posting of funds as well as streamlined payment information, but this could translate to major investments in support staff and equipment upgrades. This in turn could become a barrier for small and medium companies, which are agents as they are reluctant to adopt the FEDI. This is mainly due to the cost involved in setting up the system that must be customized to their business needs. In this context, in the second phase of this project, the researchers aim to determine the antecedents towards successful implementation of FEDI systems within the financial service sector in Malaysia.

\section{References}

1. Amin, Ahmed El. ( No date), Money by Wire, [Online], Available : http://news.center.com/, [2001, August]

2. $\quad$ Banerjee, P.R.Hackey, G.Dhillon and R.Jain,320-336, Har-Aanad Publications, PVT, Ltd.

3. Cathomen, Ivo and Klein, Stefan (1997), Development of Financial Electronic Data Interchange in Switzerland: A Life Cycle Approach, [Online], Available: http://www.gvsu.edu/, [2001,June]

4. CNET News.com, (1996, October 29), Melon Implements EDI, [Online], Available: http://new.com.com/ [2001,June]

5. Cox, B. and Ghoneim, S. (1997) "Developing a National EDI Strategy." In Business Information Technology Management: Closing the International Divide, eds.

6. Crede, Andreas (No date), E-commerce and Banking Industry: The requirement and Opportunities for New Payment System Using the Internet, [Online], Available: http://jcmc.huji.ac/ [2001, June]

7. Department of Accounts: Electronic Data Interchange, [Online], (2001, January), Available: http://www.doa.state.va.us/procedures/GeneralAccounting/EDI/edinew.htm [2001, December]

8. Department of Treasury, (2001, June 27), Vendor Payments and the Delivery of Payment-Related Information: What you need to know about the process and what to ask your financial institution. [Online], Available: http://www.fms.gov/[2001 July]

9. Farhoomand, A.F. and E. Pace (1995) " An Exploratory Investigation of Electronic Commerce Use in International Trade". In Proceedings of the $3^{\text {rd }}$ European Conference on Information Systems, 3341,eds.G.Doukidis,B. Galliers,T. Jelassi, H. Kremar and F. Land, Athens, Greece.

10. Financial Electronic Data Interchange Status, [Online], Available : http://www.uboc.com/[2001, October]

11. Galliers R.,P.Swatman. (1995) "Strategic Information Systems Planning: Deriving Comparative Advantage From EDI." Journal of Information Technology,10 (3):149-159.

12. Gebauer, Judith (No date), Modeling the IT-Infrastructure of Inter-Organizational Processes - Automation vs. Flexibility, [Online], Available : http://www.haas.berkeley.edu/ [2001, August]

13. H., David (2001, June), The Electronic Commerce Approach to Electronic Data Interchange, [Online], Available: http://www.state.me.us/ec/ecapprch/ecapprch.htm [2001, December]

14. Herd, Michael (2001, November 14), NACHA Hails Results of Federal Reserve Research on Checks and Epayments, [Online], Available: http://www.assetresource.com/ [2001, December ]

15. Horluck, Jens ( No date), User participation in the development of Inter-organizational Systems, [Online], Available : http://www.econ.au.dk [2001, July]

16. Iacovou, Charalambos L., Benbasat, Izak, and Dexter, Albert S., MIS Quarterly 19(4), (1996, February ), Electronic Data Interchange and Small Organizations: Adoption and Impact of Technology; [ Online], Available : http://www.uga.cc.edu/, [ 2001, August]

17. Knudson, Scott E., Walton II, Jack K., and Young, Florence M. (April 1994), Business-to business payments and the role of financial electronic data interchange, [Online], Available: http://www.federalreserve.gov/ [2001,June]

18. Lee, Ronald M. (No date ), Current Research on Technologies for International Electronic Commerce: Generic Electronic Trade Procedures, [Online], Available : http://www.euridis.fbk.eur.n/,[2001, June ]

19. Nevada State Bank, 2001, [Online], Available: http://www.nsbank.com/ [2001, December]

20. Norsk Hydro Asa, (No date), Across Asia Pacific: Examples of Electronic Commerce Uses, [Online], Available: http://www.annexb.com/ [2001,June] 
21. Phipps, Janet (No date), Intergovernmental Telecommunications General Government Work Group, [Online], Available : http://www.state.ia.us/government/iitt/fullreport/ggfin026.htm [2001, December]

22. Riggins, Frederick J. and Hyeun-Suk (Sue) Rhee, (1998, April ), Toward a Unified View of Electronic Commerce,[Online],Available : http://www.gatech.edu/ [2001 June]

23. Riggins, Frederick J. and Mukhopadhyay, Tridas (1999 January), Overcoming Adoption and Implementation Risks of EDI, [Online], Available: http://www.gatech.edu/ [2001 June]

24. Roberts, Bob (1995, July 28), EDI Implementation Review, [Online], Available : http://www.kinston.edu/ [2001 July]

25. Swift, Kevin (April 1995), G-179 Electronic Banking Systems: Present Status, Future Prospects, [Online], Available: http://www.buscom.com/commu/G179.html [2001, December]

26. U.S. Controller's Organization, (1999,March 5), [Online], Available:http://www.llnl.gov/ [2001 July]

27. van Diepen, Tonja ( No date ), Building blocks for electronic commerce distribution channels, [Online ], Available : http://www.sepa.tudelft.nl/ [2001, July]

28. Winand, Prof. Udo, von Kortzfleisch, Dr. Harald (F.O.), and Klausninghoff, Dipl-Kfm. (No date), Interface Management in Interorganizational Systems (IOS) to Support Vertical Cooperation Between Companies and Private Households, [Online],Available : http://www.kassel.edu/ [2001,June]

29. Reengineering the Procurement Process, [Online], Available : http://www.cebusnet.com/ [2001 July]

30. (2001, April 20), Supply Chain Collaboration Yields Efficiency, [Online], Available :http://www.itnews.com/[2001 July]

31. (2000), Making the global Connection , [Online], Available : http://www.viasafe.inc/,[2001 July]

32. (1998), Virginia: Financial Electronic Data Interchange, [Online], Available : http://www.nascio.org/ [2001 September]

33. (1998, September), E-commerce Training: A Success, [Online], Available : http://www.nish.org/ [2001 September]

34. (2000, March 2), Top E-commerce Firm Spearheads Drive into Financial Sector, [Online], Available: http://www.fingaz.co.zw/ [ 2001 , December]

35. Electronic Bill Presentment \& Payment Models, [Online], Available: http://www.phoenixhecht.com/EBPP.html [2001, December]

36. The Basics of Electronic Commerce and Electronic Data Interchange, [Online], Available : http://www.dmx.com/edibasic.htm [2001, December]

37. (2001, October), Introduction to Financial EDI, [Online], Available : http://www.state.oh.us/das/dcs/odn/ecedi/financial/intro.htm [2001, December]

38. (2001, August), Traditional EDI : Getting started with Financial EDI when using a VAN, [Online], Available : http://www.state.oh.us/das/dcs/odn/ecedi/financial/gettingstarted.htm [2001, December] 
Notes 